\title{
Elevated Sleep Disturbance among Blacks in an Urban Family Medicine Practice
}

\author{
Wilfred R. Pigeon, PhD, Kathi Heffner, PhD, Paul Duberstein, PhD, \\ Kevin Fiscella, MD, MPH, Jan Moynihan, PhD, and Benjamin P. Chapman, PhD
}

Purpose: Blacks experience a number of health disparities. Sleep disturbances contribute to poor health. This preliminary study explores whether a disparity in sleep disturbances exists among blacks compared with whites and others.

Methods: A cross-sectional study was conducted in a sample $(n=92)$ of urban primary care patients (52\% black, $46 \%$ white, and $2 \%$ other) from a university-based family medicine practice. Mean (SD) age was 51.9 years (8.9 years). Participants completed the Pittsburgh Sleep Quality Index, the Center for Epidemiologic Studies Depression Scale, Revised, and a checklist of chronic health conditions.

Results: The rate of clinically meaningful sleep disturbance was $71 \%$. In bivariate logistic regressions, black race was associated with sleep disturbance (odds ratio [OR], 3.00; 95\% CI, 1.17-7.69). Controlling for income attenuated that association by about 11\% (race 0R, 2.71; 95\% CI, 1.04-7.06). Education explained about 35\% (race 0R, 2.39; 95\% CI, 0.89-6.42). Adjustment for depression, chronic illness, and education simultaneously resulted in an estimate for race of $0 \mathrm{R}, 2.44 ; 95 \% \mathrm{CI}$, 0.85-7.01.

Conclusion: Being black is associated with a sleep disturbance that is accounted for only partially by depression, socioeconomic status, and disease burden. Black primary care patients may benefit from additional screening and monitoring of sleep difficulties. (J Am Board Fam Med 2011;24:161-168.)

Keywords: Blacks, Health Care Disparities, Insomnia, Minority Health, Sleep Disorders

Regardless of economic status, blacks in the United States experience chronic stress and consequent poor health because of social disadvantages $^{1-5}$ and stressor-related allostatic load. ${ }^{6} \mathrm{We}$ use the term "black" to refer to people who self-identify as being of African descent, a very diverse group that includes US-born African Americans whose lineages have endured slavery

This article was externally peer reviewed.

Submitted 8 February 2010; revised 29 October 2010; accepted 28 November 2010.

From the Department of Psychiatry, Sleep \& Neurophysiology Research Laboratory (WRP); Department of Psychiatry, Rochester Center for Mind-Body Research (WRP, $\mathrm{KH}, \mathrm{PD}, \mathrm{JM}, \mathrm{BPC})$; the Department of Family Medicine (KF); and the Department of Community and Preventive Medicine (KF), University of Rochester Medical Center, Rochester, NY.

Funding: Support for this work was provided by the $\mathrm{Na}-$ tional Institutes of Health (NIH) grants K23NR010408, K24MH072712, K08AG031328, R24AG031089, and R21AG023956. The views and opinions expressed by the authors do not necessarily reflect the views or opinions of the NIH. and its consequences, people of Afro-Caribbean descent, and recent immigrants from Africa. Sleep disturbance is an often unrecognized and seldom examined component of illness that contributes to health status. Poor sleep may represent a response to stress, ${ }^{7}$ a component contributing to allostatic load, ${ }^{8,9}$ and/or a mediator between psychological distress and neuroendocrine effects, leading to negative health outcomes. ${ }^{10,11}$ Thus, sleep disturbance may constitute an important contributor to health disparities among blacks.

Prior presentation: These data were presented in part as an abstract and poster at the annual meeting of the Association of Professional Sleep Societies, Seattle, WA (June 8, 2009).

Conflict of interest: none declared.

Corresponding author: Wilfred R. Pigeon, PhD, CBSM, Department of Psychiatry, Sleep \& Neurophysiology Research Laboratory, University of Rochester, 300 Crittenden Boulevard, Box PSYCH, Rochester, NY 146428409 (E-mail: Wilfred_Pigeon@URMC.rochester.edu). 
Sleep disturbances are associated with considerable morbidity ${ }^{12,13}$ and increased mortality ${ }^{14}$ and even susceptibility to developing a common cold. ${ }^{15}$ The most common form of sleep disturbance, chronic insomnia, occurs in approximately $10 \%$ of the general population and is associated with substantial economic costs and health consequences, ${ }^{16}$ including higher health care expenses, ${ }^{17}$ with direct costs estimated at US $\$ 13$ billion per annum in physician visits, prescriptions, and procedures. ${ }^{18}$ Not surprisingly, sleep disturbances, particularly insomnia, are highly prevalent among primary care patients. ${ }^{19}$ Chronic insomnia is an independent risk factor for hypertension, ${ }^{20}$ which is a key driver of the disproportionate overall illness burden in socioeconomically disadvantaged blacks.

In general, both subjective $\mathrm{e}^{21,22}$ and objective $\mathrm{e}^{22,23}$ sleep disturbances are more pronounced in individuals with lower socioeconomic status. Likewise, greater subjective $^{24}$ and objective ${ }^{25}$ sleep disturbances have been observed among blacks compared with whites, with some exceptions. ${ }^{26}$ Findings have consistently shown that blacks have higher rates of sleep apnea, ${ }^{27-29}$ shorter or longer habitual sleep durations, ${ }^{30}$ and more objective indicators of insomnia ${ }^{25}$ than whites. Subjectively, blacks report insomnia or indicators of insomnia at similar or lower rates than whites, ${ }^{31-34}$ perhaps because of under-endorsement of insomnia in some samples of black patients. ${ }^{35}$ Taken together, the available literature suggests a disparity with respect to sleep disturbances among black populations.

In this article we focus specifically on whether blacks have more sleep disturbances (measured with a validated sleep instrument) than whites and others in a clinical sample. We targeted middle-aged and older adults, given the cumulative nature of chronic illness and the increase in sleep disturbances across the life span. We recruited participants from an urban primary care setting because of the increased burden of chronic disease among socioeconomically disadvantaged urbanites. ${ }^{36} \mathrm{We}$ hypothesized that blacks would be more likely to report sleep disturbances.

\section{Methods}

\section{Participants and Procedures}

Patients aged 40 years and older were recruited in person and by flyers posted in the waiting room at the Family Medicine Center of the University of Rochester Medical Center, directing them to call a research coordinator to schedule a research appointment at the Family Medicine Center or the General Clinical Research Center $(n=107)$. The flyer and the informed consent document indicated that the time commitment for the study would be approximately 3 hours and that participants would be compensated $\$ 50$ for their participation. At the appointment, after providing written informed consent, participants completed an interview assessing demographics and psychosocial circumstances, the Pittsburgh Sleep Quality Index (PSQI) ${ }^{37}$ the Center for Epidemiologic Studies Depression Scale, Revised (CESD-R), ${ }^{38}$ and a checklist of chronic health conditions (see "Instruments," below), as well as a blood draw (these data have been reported elsewhere $^{39}$ ). Fifteen participants did not complete the PSQI; they did not differ from the rest of the sample on any demographic variables.

Respondents completing all study instruments $(\mathrm{n}=92)$ were, on average, middle-aged (mean, 51.9 years; SD, 8.91 years) and the majority were women $(77.2 \%)$. They had an income level of less than $\$ 20,000$ per year $(62 \%)$, were not currently married (73.9\%), and had children (83.7\%). A little more than one quarter of the sample did not complete high school $(26.1 \%)$. Participants were primarily black (52.2\%) and white (46.6\%), with one participant each endorsing only American Indian/ Native and other, respectively. For analyses, the latter 2 participants $(2.2 \%)$ were combined with whites into one "white/other" group. The racial diversity of the sample mirrored the diversity of the entire clinic population. Additional racial and other characteristics of the sample are further detailed in Table 1.

\section{Instruments}

\section{PSQI}

The PSQI is a 24-item scale that measures sleep disturbances along 7 dimensions. Scores from these 7 dimensions (ranging from 0-3) are individually reported as component scores and summed to derive a global sleep quality score ( $0-21)$; a score of $>5$ has been demonstrated to be indicative of a sleep disturbance. ${ }^{37}$ A subsequent reliability and validation study comparing the PSQI with sleep diaries and with objective polysomnographic measures of sleep among patients with insomnia found that using a cutoff of $>6$ resulted in the best sensitivity and specificity with respect to insomnia, ${ }^{40}$ a convention that we adopted in this study. Cronbach's $\alpha$ internal consistency in the 
Table 1. Sample Characteristics for Total Sample, Black Participants, and White/Other Participants

\begin{tabular}{|c|c|c|c|}
\hline & Total Sample & Black & White/Other \\
\hline Race & $92(100.0)$ & $48(52.2)$ & $44(48.8)$ \\
\hline Non-Hispanic white & $40(43.5)$ & 0 & 40 \\
\hline Non-Hispanic black & $44(47.8)$ & 44 & 0 \\
\hline Hispanic* & $3(3.3)$ & 2 & 1 \\
\hline American Indian or Alaska Native ${ }^{\dagger}$ & $4(4.3)$ & 2 & 2 \\
\hline Other & $1(1.1)$ & 0 & 1 \\
\hline Age (mean yr [range]) & $51.9(40-80)$ & $51.3(40-80)$ & $52.5(40-79)$ \\
\hline Female sex & $71(77.2)$ & $39(81.3)$ & $32(72.7)$ \\
\hline \multicolumn{4}{|l|}{ Education } \\
\hline No high school diploma & $24(26.1)$ & $16(33.3)$ & $8(18.2)$ \\
\hline GED or graduated from high school & $21(22.8)$ & $14(29.2)$ & $7(14.6)$ \\
\hline Some college & $8(8.7)$ & $3(6.3)$ & $5(10.4)$ \\
\hline Associate's degree or 2 years of college & $23(25.0)$ & $13(27.1)$ & $10(20.8)$ \\
\hline College graduate & $10(10.9)$ & $1(2.1)$ & $9(18.8)$ \\
\hline Graduate degree & $6(6.5)$ & $1(2.1)$ & $5(10.4)$ \\
\hline \multicolumn{4}{|l|}{ Employment status } \\
\hline Employed (total) & $27(29.3)$ & $13(27.1)$ & $14(31.8)$ \\
\hline Full time & $17(18.5)$ & $10(20.8)$ & $7(15.9)$ \\
\hline Part time & $10(10.9)$ & $3(6.3)$ & $7(15.9)$ \\
\hline Unemployed (total) $^{\ddagger}$ & $65(70.7)$ & $35(72.9)$ & $30(68.2)$ \\
\hline Homemaker & $2(2.2)$ & $1(2.1)$ & $1(2.1)$ \\
\hline Retired & $8(8.7)$ & $3(6.3)$ & $5(11.4)$ \\
\hline Receiving disability & $37(40.2)$ & $19(39.6)$ & $18(40.9)$ \\
\hline Looking for paid work & $17(18.5)$ & $13(27.1)$ & $4(9.1)$ \\
\hline Not looking for paid work & $15(16.3)$ & $7(14.6)$ & $8(18.2)$ \\
\hline \multicolumn{4}{|l|}{ Household income level (per year) } \\
\hline$<\$ 20,000$ & $57(62.0)$ & $34(70.8)$ & $23(52.3)$ \\
\hline$\geq \$ 20,000$ & $35(38.0)$ & $14(29.2)$ & $21(47.7)$ \\
\hline
\end{tabular}

Values provided as $\mathrm{n}(\%)$ unless otherwise indicated.

*Two Hispanic participants also endorsed black; the other endorsed white.

${ }^{\dagger}$ Two American Indian/Native Alaskan participants also endorsed black; one also endorsed white; and the other endorsed only American Indian/Native Alaskan.

${ }^{\ddagger}$ Some respondents endorsed more than one category of unemployment status.

GED, General Educational Development.

current sample was 0.78 , which compares with the 0.83 reported in the original validation study. We report the global score and each of the component scores, as well as 2 single items from the scale, that are useful self-report measures of sleep continuity disturbance observed in insomnia samples. These were total sleep duration (dichotomized at 6.5 hours) and sleep efficiency, which is the ratio of time spent in bed to total sleep duration (dichotomized at $85 \%$ ).

\section{CESD-R}

The CESD-R is a 20-item measure of depressive symptoms during the previous week. ${ }^{38}$ Responses involve a 4-point Likert scale ranging from 0 ("not at all") to 3 ("nearly every day"). Cronbach's $\alpha$ internal consistency in the current sample was 0.93 . For descriptive purposes we report both the total CESD-R scores and total score with the sleep items removed, though only the latter were used in analyses.

\section{Other Health Factors}

Patients completed a checklist of chronic conditions adapted from that used in the Midlife Development in the United States survey. ${ }^{41}$ The selfreport checklist asks, Has a doctor ever told you you've had any of the following problems? Place a number to the left of each problem below: $0=$ never; $1=$ previously had this; $2=$ have this now or within the last year. The 25 common chronic med- 
ical conditions span respiratory, gastrointestinal, neurological, endocrine, and cardiovascular problems; conditions include "asthma," "recurring backache," "diabetes," and "persistent trouble with your mouth or gums." All items rated a 2 were summed to form a morbidity index. ${ }^{42}$ Body weight was also available from primary care charts for approximately $90 \%$ of the sample.

\section{Statistical Analysis}

After descriptive statistics, a series of bivariate logistic regressions were conducted, with sleep disturbance (PSQI $>6$ ), sleep duration $(<6.5$ hours per night), and sleep efficiency $(<85 \%)$ as the dependent variables. The main predictor of interest was race (black vs white/other); additional predictors were sex, employment status (employed versus unemployed), annual household income $(<\$ 20,000$ vs $\geq \$ 20,000$ per year), education level (no high school diploma vs high school diploma vs a college degree), depressive symptoms (by CESD-R quartile with sleep items removed), and disease burden (Morbidity Index). We also considered age and body weight as potential covariates. We tested each covariate separately in models predicting PSQI $>6$ from race, and subsequently included all significant covariates in the final model. To examine if any of the other predictors explained observed associations between race and sleep disturbance, we computed the change in estimate that resulted from including each variable in the model ([unadjusted odds ratio $\{\mathrm{OR}\}$ for race - adjusted OR for race] / [unadjusted OR for race -1$]$ ). Although neither the CESD-R category absent sleep items nor the Morbidity Index differed by race or by income, we conservatively adjusted for depression and common medical conditions. Finally, to further assess whether specific chronic illnesses were associated with sleep disturbance, contingency analyses were conducted for the presence or absence of specific conditions derived from the self-reported checklist) and PSQI scores above or below our cutoff. All analyses were conducted using SPSS software version 17.0 (SPSS, Inc., Chicago, IL).

\section{Results}

\section{Descriptive Findings}

Descriptive statistics for the global PSQI, the 7 PSQI component scores, the sleep duration and efficiency items, the depressive symptomatology score from the CESD-R (excluding the sleep
Table 2. Mean (SD) Scores for Sleep Quality Depression and Chronic Illness Morbidity for the Urban Primary Care Patients $(\mathrm{n}=\mathbf{9 2})$

\begin{tabular}{lc}
\hline Variable & Mean (SD) \\
\hline PSQI global sleep quality & $10.00(4.88)$ \\
PSQI components & \\
1. Subjective sleep quality & $1.57(0.96)$ \\
2. Sleep latency & $1.70(1.08)$ \\
3. Sleep duration & $1.28(1.14)$ \\
4. Sleep efficiency & $1.26(1.23)$ \\
5. Sleep disturbance & $1.96(0.80)$ \\
6. Use of sleep medication & $1.17(1.34)$ \\
7. Daytime dysfunction & $1.22(0.84)$ \\
PSQI items & \\
Average sleep duration (hr) & $5.83(1.77)$ \\
Habitual sleep efficiency (\%) & $75.00(20.10)$ \\
Depression & \\
CESD-R & $17.19(12.37)$ \\
CESD-R (minus sleep items) & $14.10(11.90)$ \\
Morbidity index & $4.1(3.1)$ \\
\hline
\end{tabular}

PSQI, Pittsburgh Sleep Quality Index; CESD-R, Center for Epidemiological Studies Depression Scale, Revised.

items), age, body weight, and morbidity are presented in Table 2. Using a cutoff of 6 to identify the presence of clinical sleep disturbance or insomnia, $70.7 \%$ of the sample $(n=65)$ scored above the cutoff. The high mean (sd) PSQI global score of 10.0 (4.9) is elevated compared with a healthy sample and a sample with suspected sleep apnea, and it is comparable to values observed in an insomnia sample from the original PSQI validation studies. ${ }^{37}$

Using the CESD-R (including the sleep items) to classify individuals who have a moderate to high likelihood of major depression, $46.7 \%(n=43)$ met the standard CESD-R cutoff of $16 ; 33.7 \%(n=31)$ met the higher suggested cutoff of 21 for older adults. ${ }^{43}$ As might be expected, Pearson correlation coefficients showed that the CESD-R score (excluding the sleep items) was correlated with poorer global sleep quality $(\mathrm{r}=0.53 ; P<.001)$, shorter sleep duration $(\mathrm{r}=0.24 ; P<.05)$, and lower sleep efficiency $(\mathrm{r}=0.23 ; P<.05)$. Patients with and without sleep disturbances did not significantly differ by age (PSQI global sleep quality score $>6$ mean, 51.14; SD, 7.71; PSQI score $\leq 6$ mean, 53.59; SD, 11.28; $P=.23$ ) or body weight (PSQI global sleep quality score $>6$ mean, 201.23; SD, 42.78; PSQI score $\leq 6$ mean, 196.22; SD, 46.17; $P=.62)$. The differences in Morbidity Index scores for patients with and without sleep disturbances 
approached statistical significance (PSQI global sleep quality score $>6$ mean, 4.42 ; SD, 3.34; PSQI score $\leq 6$ mean, $3.11 ; \mathrm{SD}, 2.12 ; P=.06$ ).

\section{Sleep Disturbance and Race}

Binary logistic regression models predicting sleep disturbance (PSQI global sleep quality score $>6$ ) are presented in Table 3. Black race was related to the presence of sleep disturbance (OR, 3.00; 95\% CI, 1.17-7.69) in the unadjusted model (model 1). In subsequent models that adjusted for sex, employment status, income category $(\geq \$ 20,000$ or $<\$ 20,000$ per year), education, CESD-R quartile, and chronic disease morbidity, race remained associated with global sleep quality (models 2 to 7 ). Only 2 predictors explained [my] $10 \%$ of the association between race and sleep disturbance: income (attenuation in $\mathrm{OR}=[3.0-2.79] /[3.0-1]=$ $0.105)$ explained roughly $10.5 \%$ and education $([3.0-2.31] /[3.0-1]=0.345)$ explained $34.5 \%$ of the risk associated with black race. Including all significant covariates in a model simultaneously (full model) yielded an association between race and sleep disturbance that was comparable in magnitude to the unadjusted association (OR, 2.44; $95 \%$ CI, 0.85-7.01). This same pattern of findings was observed in models using sleep duration $(<6.5$ hours per night) as the dependent variable, although race was not a significant predictor in models using sleep efficiency $(<85 \%)$ as the dependent variable (data not shown).

\section{Discussion}

There was a high rate of sleep disturbance in this urban primary care sample $(>70 \%)$. The mean global PSQI score in the sample was higher than that typically observed in samples of sleep apnea patients ${ }^{37,44,45}$ and was similar to the level of severity observed among patients suffering from primary insomnia, ${ }^{37}$ hemodialysis patients, ${ }^{46}$ and patients with lung cancer. ${ }^{47}$ Most notably, race was a significant independent correlate of sleep disturbance. This finding from a clinical sample is similar to that observed by Hall et $\mathrm{al}^{22}$ in a recent multisite community study of midlife women.

In the current study, being black was related to roughly 3 times the odds of having a sleep disturbance compared with being white/other. Race remained a significant correlate of sleep disturbance after controlling for income, employment, and a number of other factors, which explained approximately $\leq 10 \%$ of the association. Controlling for education, however, explained roughly $35 \%$ of the risk associated with race. Further longitudinal work might examine the biopsychosocial mechanisms causing these findings. The role of chronic stress and unmeasured lifestyle factors such as diet and exercise will be important to consider.

Limitations of this study include its cross-sectional nature, which prohibits any causal interpretations of these findings; the relatively small sample size; and the collection of data from only one primary care setting, which is not representative of the general population and may not represent other urban community samples. In addition, neither medication status nor body mass index were available in a manner that could be subjected to rigorous analysis, though both can contribute to sleep disturbance. Groups did not differ with respect to the PSQI component that measures sleep medications and several correlates of obesity (weight that was available from chart review, presence of diabetes taken from the chronic condition checklist, and presence of snoring derived from PSQI item 5e). It is also possible that the generally low educational level of this cohort may have introduced random error in responses on self-report instruments. This would make it less, rather than more, likely to detect associations. Finally, our overall sample was generally low on all socioeconomic indicators and contained mostly women, which limited the generalizability of the findings.

Notwithstanding these limitations, the strengths of the study include the use of a validated sleep instrument in an ethnically diverse sample to assess the contributions of race to sleep disturbance severity while adjusting for levels of depression and disease burden. The findings support the notion that a disparity exists for blacks with respect to sleep disturbances. Such results indicate a need for large-scale prevalence studies to determine whether this estimate is broadly generalizable. It will be important to test whether higher chronic stress is a key contributor to higher rates of poor sleep among blacks. Further work is needed about whether midlife and older black patients in urban primary care settings may benefit from screening and/or increased monitoring for sleep problems.

Screening and monitoring is important for several reasons. First, sleep disturbance is becoming increasingly recognized as a risk factor for signifi- 


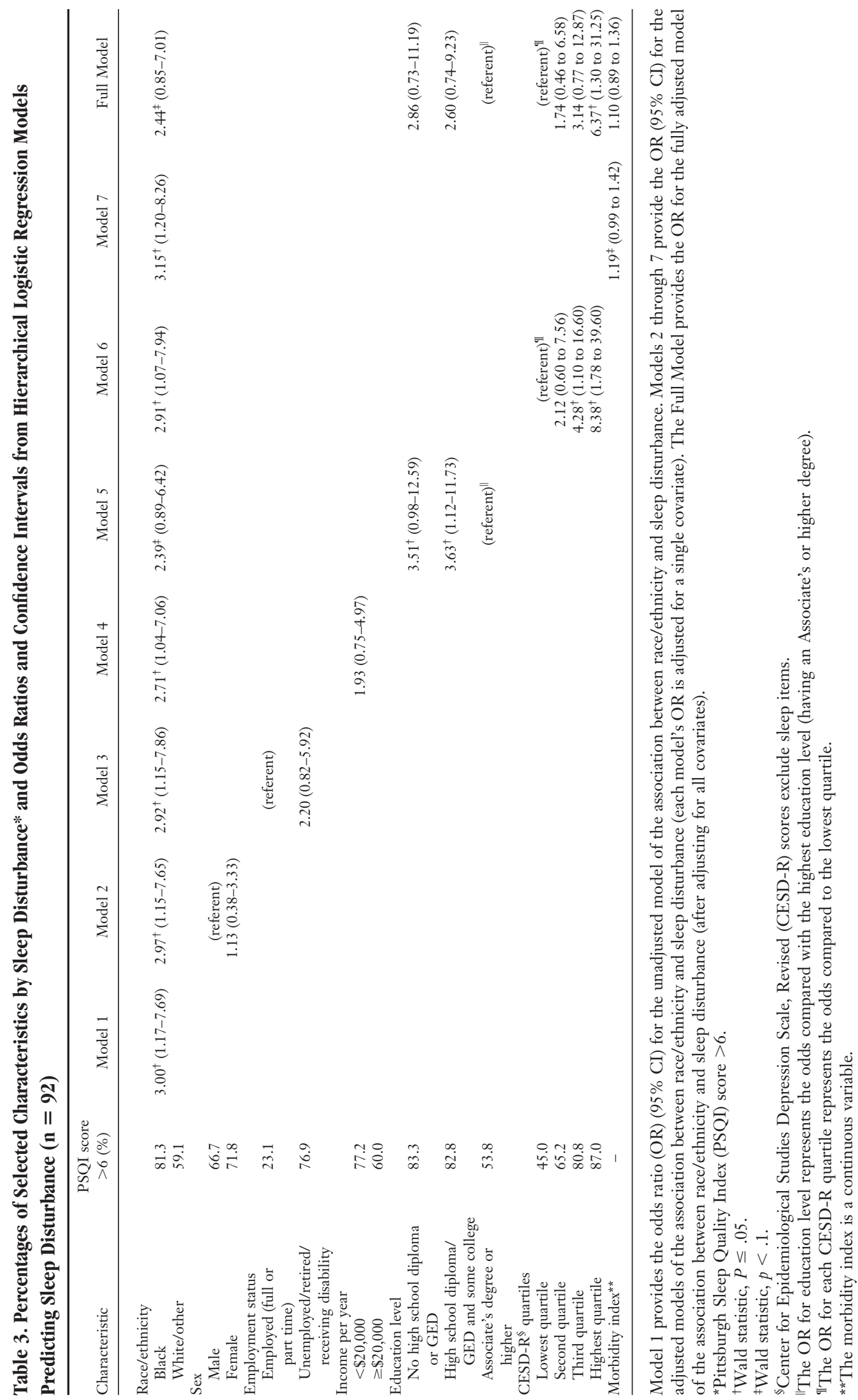


cant morbidity and, to some extent, mortality. With respect to blacks in particular, further work is needed to test the extent to which sleep disturbances independently contribute to the established higher prevalence rates of hypertension and cardiovascular disease among these populations. Second, most common sleep disturbances can be effectively treated, but they remain vastly under-recognized and under-treated. ${ }^{13,48}$ Efficacious behavioral sleep medicine interventions, which could be integrated into primary care settings, exist for a variety of sleep disturbances. ${ }^{49}$ Finally, although the general population has poor access to such specialty services, it is likely that access is worse in traditionally underserved populations. Cost-effective means to deliver interventions for sleep disturbances in the primary care context merit consideration.

\section{References}

1. Geronimus AT, Hicken M, Keene D, Bound J. "Weathering" and age patterns of allostatic load scores among blacks and whites in the United States. Am J Public Health 2006;96:826-33.

2. Williams DR. African-American health: the role of social environment. J Urban Health 1998;75:300-21.

3. Williams DR, Rucker TD. Understanding and addressing racial disparities in health care. Health Care Financ Rev 2000;21:75-90.

4. Berkman LF, Glass T. Social integration, social networks, social support, and health. In: Berkman LF, Kawachi I, eds. Social epidemiology. New York: Oxford University Press; 2000:137-73.

5. Williams DR. Race, socioeconomic status, and health. The added effects of racism and discrimination. Ann N Y Acad Sci 1999;896:173-88.

6. Carlson ED, Chamberlain RM. Allostatic load and health disparities: a theoretical orientation. Res Nurs Health 2005;28:306-15.

7. Drake C, Richardson G, Roehrs T, Scofield H, Roth T. Vulnerability to stress-related sleep disturbance and hyperarousal. Sleep 2004;27:285-91.

8. Mcewen BS, Wingfield JC. The concept of allostasis in biology and biomedicine. Horm Behav 2003;43: $2-15$.

9. Mcewen BS. Sleep deprivation as a neurobiologic and physiologic stressor: allostasis and allostatic load. Metabolism 2006;55:S20-3.

10. Cohen S, Doyle WJ, Alper CM, Janicki-Deverts D, Turner RB. Sleep habits and susceptibility to the common cold. Arch Intern Med 2009;169:62-7.

11. Vgontzas AN, Bixler EO, Lin HM, et al. Chronic insomnia is associated with nyctohemeral activation of the hypothalamic-pituitary-adrenal axis: clinical implications. J Clin Endocrinol Metab 2001;86: 3787-94.
12. Taylor DJ, Mallory LJ, Lichstein KL, Durrence $\mathrm{HH}$, Riedel BW, Bush AJ. Comorbidity of chronic insomnia with medical problems. Sleep 2007;30: 213-8.

13. Committee on Sleep Medicine and Research, Colten HR, Altevogt BM. Sleep disorders and sleep deprivation: an unmet public health problem. Washington D.C.: The National Academies Press; 2006.

14. Dew MA, Hoch CC, Buysse DJ, et al. Healthy older adults' sleep predicts all-cause mortality at 4 to 19 years of follow-up. Psychosom Med 2003;65:63-73.

15. Cohen S, Alper CM, Doyle WJ, Adler N, Treanor JJ, Turner RB. Objective and subjective socioeconomic status and susceptibility to the common cold. Health Psychol 2008;27:268-74.

16. National Institutes of Health State of the Science Conference statement on Manifestations and Management of Chronic Insomnia in Adults, June 13-15, 2005. Sleep 2005;28:1049-57.

17. Ozminkowski RJ, Wang SH, Walsh JK. The direct and indirect costs of untreated insomnia in adults in the United States. Sleep 2007;30:263-73.

18. Walsh JK, Engelhardt CL. The direct economic costs of insomnia in the United States for 1995. Sleep 1999;22(Suppl 2):S386-93.

19. Shochat T, Umphress J, Israel AG, Ancoli-Israel S. Insomnia in primary care patients. Sleep 1999; 22(Suppl 2):S359-65.

20. Suka M, Yoshida K, Sugimori H. Persistent insomnia is a predictor of hypertension in Japanese male workers. J Occup Health 2003;45:344-50.

21. Arber S, Bote M, Meadows R. Gender and socioeconomic patterning of self-reported sleep problems in Britain. Soc Sci Med 2009;68:281-9.

22. Hall MH, Matthews KA, Kravitz HM, et al. Race and financial strain are independent correlates of sleep in midlife women: the SWAN sleep study. Sleep 2009;32:73-82.

23. Mezick EJ, Matthews KA, Hall M, et al. Influence of race and socioeconomic status on sleep: Pittsburgh SleepSCORE project. Psychosom Med 2008;70: 410-6.

24. Baker FC, Wolfson AR, Lee KA. Association of sociodemographic, lifestyle, and health factors with sleep quality and daytime sleepiness in women: findings from the 2007 National Sleep Foundation "Sleep in America Poll." Journal Womens Health (Larchmt) 2009;18:841-9.

25. Lauderdale DS, Knutson KL, Yan LJL, et al. Objectively measured sleep characteristics among earlymiddle-aged adults: the CARDIA study. Am J Epidemiol 2006;164:5-16.

26. Blazer DG, Hays JC, Foley DJ. Sleep complaints in older adults: a racial comparison. Journals Gerontology A Biol Sci Med Sci 1995;50:M280-4.

27. Redline S, Tishler PV, Hans MG, Tosteson TD, Strohl KP, Spry K. Racial differences in sleep-disor- 
dered breathing in African-Americans and Caucasians. Am J Respir Crit Care Med 1997;155:186-92.

28. Ancoli-Israel S, Klauber MR, Stepnowsky C, Estline E, Chinn A, Fell R. Sleep-disordered breathing in African-American elderly. Am J Respir Crit Care Med 1995;152:1946-9.

29. Girardin JL, von Gizycki H, ZIzi F, Dharawat A, Lazar JM, Brown CD. Evaluation of sleep apnea in a sample of black patients. J Clin Sleep Med 2008;4: 421-5.

30. Nunes J, Jean-Louis G, Zizi F, et al. Sleep duration among black and white Americans: Results of the National Health Interview Survey. J Natl Med Assoc 2008;100:317-22.

31. Bixler EO, Kales A, Soldatos CR, Kales JD, Healey S. Prevalence of sleep disorders in the Los Angeles metropolitan area. Am J Psychiatry 1979;136: $1257-62$.

32. Durrence HH, Lichstein KL. The sleep of African Americans: a comparative review. Behav Sleep Med 2006;4:29-41.

33. Hicks RA, Lucero-Gorman K, Bautista J, Hicks GJ. Ethnicity, sleep duration, and sleep satisfaction. Percept Mot Skills 1999;88:234-5.

34. Hicks RA, Lucero-Gorman K, Bautista J, Hicks GJ. Ethnicity, sleep hygiene knowledge, and sleep hygiene practices. Percept Mot Skills 1999;88:1095-6.

35. Jean-Louis G, Magai C, Pierre-Louis J, et al. Insomnia complaints and repressive coping among black and white Americans. Sleep 2005;28:A232.

36. Fiscella K, Williams DR. Health disparities based on socioeconomic inequities: Implications for urban health care. Acad Med 2004;79:1139-47.

37. Buysee DJ, Reynolds CF 3rd, Monk TH, Berman SR, Kupfer DJ. The Pittsburgh Sleep Quality Index: a new instrument for psychiatric practice and research. Psychiatry Res 1989;28:193-213.

38. Eaton WW, Smith C, Ybarra M, Muntaner C, Tien A. Center for Epidemiologic Studies Depression Scale: review and revision (CESD and CESD-R). In: Maruish ME, ed. The use of psychological testing for treatment planning and outcomes assessment:
Vol. 3: instruments for adults. Princeton, NJ: Lawrence Erlbaum Associates; 2004;363-77.

39. Chapman BP, Khan A, Harper M, et al. Gender, race/ethnicity, personality, and interleukin-6 in urban primary care patients. Brain Behav Immun 2009; 23:636-42.

40. Backhaus J, Junghanns K, Broocks A, Riemann D, Hohagen F. Test-retest reliability and validity of the Pittsburgh Sleep Quality Index in primary insomnia. J Psychosom Res 2002;53:737-40.

41. Brim OG, Ryff CD, Kessler RC. The MIDUS national survey: an overview. In: Brim OG, Ryff CD, Kessler RC, eds. How healthy are we? A national study of well being at midlife. Chicago: University of Chicago Press; 2004:1-34.

42. Fortin M, Bravo G, Hudon C, Vanasse A, Lapointe L. Prevalence of multimorbidity among adults seen in family practice. Ann Fam Med 2005;3:223-8.

43. Lyness JM, Noel TK, Cox C, King DA, Conwell Y, Caine ED. Screening for depression in elderly primary care patients. A comparison of the Center for Epidemiologic Studies-Depression Scale and the Geriatric Depression Scale. Arch Intern Med 1997; 157:449-54.

44. Kezirian EJ, Harrison SL, Ancoli-Israel S, et al. Behavioral correlates of sleep-disordered breathing in older men. Sleep 2009;32:253-61.

45. Kezirian EJ, Harrison SL, Ancoli-Israel S, et al. Behavioral correlates of sleep-disordered breathing in older women. Sleep 2007;30:1181-8.

46. Iliescu EA, Coo H, McMurray MH, et al. Quality of sleep and health-related quality of life in haemodialysis patients. Nephrol Dial Transplant 2003;18: 126-32.

47. Shochat T, Tzischinsky O, Oksenberg A, Peled R. Validation of the Pittsburgh Sleep Quality Index Hebrew translation (PSQI-H) in a sleep clinic sample. Isr Med Assoc J 2007;9:853-6.

48. Lamberg L. Despite effectiveness, behavioral therapy for chronic insomnia still underused.JAMA 2008;300:2474-5.

49. Pigeon WR, Crabtree VM, Scherer MR. The future of behavioral sleep medicine. J Clin Sleep Med 2007; 3:73-9. 